\section{Exposure to bisphenol $A$ and gender differences: from rodents to humans evidences and hypothesis about the health effects}

\section{Lidia Caporossi, Bruno Papaleo \\ Department of Occupational and} Environmental Medicine, Epidemiology and Hygiene, Italian National Institute for Insurance against Occupational Accidents (INAIL), Monteporzio Catone (RM), Italy

\section{Abstract}

Bisphenol A (BPA) interacts with the endocrine system and seems to produce different effects in relation to gender. The objective of the study was to clarify the possible health effects of exposure to BPA in relation to gender. A literature search was performed using three different search engines: Medline, PubMed and Scopus. Data on both animals and humans showed that BPA acts as a xenoestrogen and interacts with the androgens' metabolism, producing different outcomes: uterotropic effects, decreasing sperm production, stimulation of prolactin release. Gender difference plays a key role in understanding the real toxic effects, the BPA serum concentrations were, all the time, higher in male subjects, possibly due to the difference in androgen-related enzyme activity levels, compared with the healthly female subjects, to equal levels of exposure; while higher BPA levels in women have been associated with a variety of conditions including obesity, endometrial hyperplasia, recurrent miscarriages, and polycystic ovarian syndrome. The data collected are sufficiently robust to raise concerns about the potentially deleterious impact of BPA on humans, even with some methodological limitations; the different impact of BPA in men and in women is documented and of a certain interest. In toxicology it is necessary to assess effects in relation to gender differences, in order to set up prevention plans in the work environment targeting the specific risk.

\section{Introduction}

Differences in exposure, anatomy, physiology, biochemistry and behavior between males and females are a dominant theme in biology, transcending the plant and animal kingdoms.

The variables that create differences between male and female could be summed up as follows: anatomical (significant organ mass differences, blood volume and flow rates), physiological (ventilation rates, water intake), discretionary (diet, smoking, pharmaceuticals) and occupational (even in the same job men and women often encounter different levels of exposure). ${ }^{1}$ Furthermore, gender-specific organs respond differently to xenobiotics, although controversy persists on this subject. There has been substantial research on gender differences in synthesis and release of proteins and hormones, up- or down- regulation of receptors, non-steroidal agonists, antagonists for receptors, altered metabolism, altered transport quantity or free:bound ratio. ${ }^{2}$

Toxicokinetic differences mainly involve metabolism: for example males and females differ in the liver metabolism of organic anions $^{3}$ and demonstrate a complex pattern of gender-specific expression of organic aniontransporting polypeptides; phase II of the metabolism (reactions of formation of glucuronides, acetylation, methylation, conjugation with sulfate, glutathione or amino acids) is generally faster in men than in women. ${ }^{4}$ Few differences are demonstrated in the absorption $^{5}$ phase; women have a lower average body weight, higher body fat composition, smaller plasma volume and lower average organ blood flow than men, these factors affect the rate and extent of distribution of chemicals; ${ }^{6}$ furthermore, sex hormones also influence the binding of chemicals to proteins in plasma, thereby leading to differences in pharmacokinetic parameters for certain chemicals. ${ }^{6}$ Few studies have been published about differences in excretion and storage of toxicants in organs, but, on average, females have proportionally more body fat than males ${ }^{7}$ and hence they may store relatively more lipophilic contaminants; in addition, females who are calcium-deficient, may store divalent compounds in their bone in lieu of calcium; males have proportionally higher rates of renal clearance ${ }^{8}$ so females may retain a higher proportion of a contaminant, even when it has been metabolized. In addition, lifestyle, psychosocial and hormonal factors modify kinetics and responsiveness.

Many occupational epidemiological studies, on which much of our understanding of toxic effects is based, begin by excluding women and minorities, though gender-related differences in responses to chemicals should be taken into account by scientists, regulators and policymakers as well as by the public. ${ }^{9}$ Some researchers have questioned the relevance of possible gender differences in acute exposure to chemicals in the same settings and in particular whether the amount of substance that is absorbed and reaches the target sites is the same for males and females: examples from the literature show that, depending on the chemical compound, there may be gender differences in exposure, due especially to the different pos-
Correspondence: Lidia Caporossi, Department of Occupational and Environmental Medicine, Epidemiology and Hygiene, Italian National Institute for Insurance against Occupational Accidents (INAIL), via Fontana Candida 1, 00040 Monteporzio Catone (RM), Italy.

Tel.: +39.06.94181277 - Fax: +39.06.94181456. E-mail: l.caporossi@inail.it

Key words: Bisphenol A; gender; estrogen.

Contributions: LC, conception and design of the work, acquisition, analysis and interpretation of data; drafting the work; final approval of the version to be published. BP, revising the work critically, final approval of the version to be published

Conflict of interest: the authors declare no conflict of interest.

Received for publication: 12 May 2015.

Revision received: 23 June 2015.

Accepted for publication: 23 June 2015.

This work is licensed under a Creative Commons Attribution NonCommercial 3.0 License (CC BYNC 3.0).

(C)Copyright L. Caporossi and B. Papaleo, 2015 Licensee PAGEPress, Italy

Journal of Xenobiotics 2015; 5:5264

doi:10.4081/xeno.2015.5264

sibility of metabolism, storage and excretion. ${ }^{10}$

Bisphenol A (BPA) is a major industrial chemical used, as a monomer, in production of polycarbonates plastics, as a component in epoxy resin, as an antioxidant in polyvinylchloride (PVC) plastics and as an inhibitor of end polymerization in PVC and a variety of other applications. Annual production within the European Union (EU) amounts to approx. 700,000 tones. ${ }^{11}$ Human exposure to BPA may occur during occupational scenarios and due to migration of BPA from food contact material into food. ${ }^{12}$ For occupational scenarios, inhalation of BPA in the form of dust is the most significant pathway of exposure expected; ${ }^{13}$ estimated exposure through inhalation and dermal exposure are both based on measured data from industry (often with problems due to different sampling design and methodology). Dietary exposure is very relevant (mainly from wine consumption and canned food). ${ }^{14}$

In literature various studies indicate that reproductive and endocrine-related endpoints are important in risk assessment of BPA. ${ }^{15,16}$

This compound is estrogenic both in vitro and in vivo: in vitro studies utilizing various test systems, mainly a human breast cancer cell line, have shown that BPA both binds to and activates estrogen receptors, including human estrogen receptor (ER) $\alpha$ and ER $\beta$, but is a weak estrogen, with an affinity/activity 
about 3-5 orders of magnitude weaker than 17 - $\beta$-estradiol, on a molar basis. ${ }^{17}$ The data on the toxicokinetics of BPA show much lower bioavailability of the parent compound following oral administration, compared with others, together with the information that the principle metabolite of BPA, the monoglucuronide conjugate, does not bind to or activate the estrogen receptor. ${ }^{14}$

\section{Materials and Methods}

The present study aims to illustrate the research conducted to identify the differences between men and women in exposure to BPA, with regard to potential health effects.

A literature search was performed using three different search engines: Medline, PubMed and Scopus. We mainly collected articles published in the last twenty years.

\section{Gender difference in experimental animals exposed to bisphenol $A$}

BPA might affect the metabolism of testosterone hydroxylation, creating a vicious cycle between BPA and androgen (Figure 1); ${ }^{18}$ it was reported that BPA treatment decreased uridine diphosphate-glucuronosyl transferase (UGT) activities toward sex hormones and BPA in the livers of male rats but not of female rats. ${ }^{19}$

Anatomical evidence of alterations in brain sexual differentiation were examined in male and female offspring, born to mouse dams exposed to 0.25/250 ng BPA/kg body weight per day ( $\mathrm{kg}$ bw/d), from the evening of day 8 of gestation through day 16 of lactation: a study was carried out on the sexually dimorphic population of tyrosine hydroxylase (TH) neurons in the brain region used for estrous cyclicity and estrogen-positive feedback. Significant sex differences in TH neuron number were observed, with a decline in BPA-exposed females; these data indicate that BPA may be capable of altering important events during critical periods of brain development, with evident gender differences. ${ }^{20}$

An investigation of exposure to BPA of pregnant female Wistar rats, during gestation and lactation, showed that BPA causes a loss of gender difference in the rat as concerns the number of corticotrophin-releasing hormone immunoreactive (CRH) neurons in the bed nucleus of the stria terminalis (BTS): usually female rats contained significantly more $\mathrm{CRH}$ neurons than male rats in the preoptic area (POA) and in the BTS, this significant sex difference was also evident in the BPA exposed group for CRH in POA but not in the BTS, suggesting that the exposure to BPA affects the CRH neurons in the BTS only for female rats. ${ }^{21}$

Pregnant Sprague Dawley rats were exposed to low concentration of BPA, near the no- observed-adverse-effect level, $5 \mathrm{mg} / \mathrm{kg} \mathrm{bw} / \mathrm{d}$, and researchers observed that low oral dose of BPA increases volume of the sexually dimorphic necleus of the POA in male, but not female, rats and, at these levels of concentration BPA treatment did not alter any other endpoint.22

Some authors have studied the effects on non-reproductive behaviors between adolescent mice exposed to BPA: levels from 40 to 400 $\mu \mathrm{g} / \mathrm{kg} / \mathrm{d}$, in the long term, altered characteristic differences in certain non-reproductive behaviors of male and female mice, including exploration, anxiety, ${ }^{23}$ spatial learning, memory and passive avoidance memory ${ }^{24}$ although no obvious changes were found in the serum hormone levels or in the weights of reproductive organs. ${ }^{25}$

To examine the impact of BPA on estrogen receptor expression in sexually dimorphic brain regions of prepubertal and adult female rats, animals were exposed to low levels of BPA (2.5-2700 $\mu \mathrm{g} \mathrm{BPA} / \mathrm{kg} \mathrm{bw} / \mathrm{d})$ and researchers found a significant decreases in estrogen receptor expression in different area of the hypothalamus. ${ }^{26}$ Particularly long evans neonatal rats were exposed to $50 \mu \mathrm{g} / \mathrm{kg}$ BPA by subcutaneous injection daily and results showed that: ER expression was augmented by BPA in postnatal day (PND) 4 females, then fell to male-typical levels by PND 10; ER $\beta$ expression was not altered by BPA on PND 4 but significantly decreased in both sexes by PND 10; kisspeptin expression was diminished by BPA in anterior hypothalamus, especially in females. ${ }^{27} \mathrm{~A}$ study on the BPA metabolism indicated $^{28}$ that serum concentrations of BPA in rats were significantly higher in males
$(24.9 \pm 7.38 \mathrm{ng} / \mathrm{mL})$ than females $(8.27 \pm 3.11$ $\mathrm{ng} / \mathrm{mL}$ ), as in humans. The resultant enzyme reaction products of BPA glucuronidation in the rat liver microsomal fraction were analyzed [messenger ribonucleic acid (mRNA) expression of UGT] and the level was significantly higher in female than in male rat livers. The gender difference in serum BPA concentrations may be explained by the difference in clearance based on UGT activities.

Other differences were evident in the research of van Esterik et al..$^{29}$ where hybrid mice (C57BL/6JxFVB) were exposed during gestation and lactation to 8 non toxic doses of BPA $(0-3000 \mu \mathrm{g} / \mathrm{kg} / \mathrm{d})$ : adult male offspring showed dose-dependent increases of body and liver weights while female offspring showed a dose dependent decrease in body weight, liver, muscle and fat pad weights, adipocyte size, serum lipids, serum leptin and adiponectin. The effects in females were more reliable and robust than in males due to wide confidence intervals and potential confounding by littler size for male data. These results suggest that BPA can program for an altered metabolic phenotype.

In an attempt to extrapolate the data obtained in animals compared to human data, Taylor et al. ${ }^{30}$ measured unconjugated and conjugated BPA levels in serum from adult female rhesus monkeys and adult female mice after oral administration of BPA and compared findings with prior published data in women: 400 $\mu \mathrm{g} / \mathrm{kg}$ of deuterated BPA (dBPA) was daily administered; mice and monkeys cleared unconjugated serum BPA at virtually identical rates; the BPA pharmacokinetics in women, female mice and monkeys were very similar.

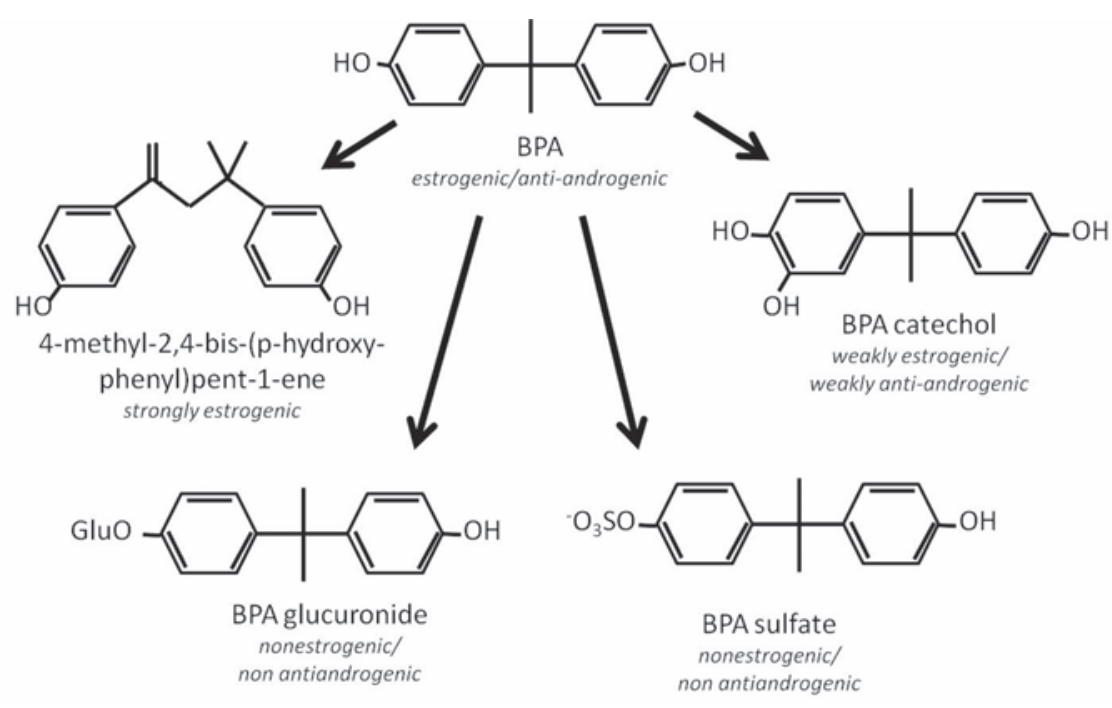

Figure 1. Major metabolites of bisphenol A (BPA) and their ability as endocrine simulators. 


\section{Gender difference in humans exposed to bisphenol $A$}

In one study researchers investigated the BPA levels in blood samples from 37 mothers between weeks 32 and 41 of gestation and after births. Placental tissue and umbilical cord blood were also analyzed: fetal plasma concentrations were higher in male than in female human fetuses. ${ }^{31}$ There is some evidence that the range of BPA levels measured may be related to gender differences in metabolization of parent BPA.

A small Korean study ${ }^{32}$ (30 subjects) reported sex differences in urinary conjugates of BPA while total BPA concentrations were similar in men and women $(2.82 \pm 0.73$ and $2.76 \pm 0.54 \mathrm{ng} / \mathrm{mL}$, respectively). In this study men were more likely to glucuronidate BPA $(2.34 \pm 0.85 \mathrm{ng} / \mathrm{mL})$ than women $(1.00 \pm 0.34$ $\mathrm{ng} / \mathrm{mL}$ ), but women appeared to have a metabolic shunt for the sulfation of BPA $(1.20 \pm 0.32$ $\mathrm{ng} / \mathrm{mL}$ vs $0.49 \pm 0.27 \mathrm{ng} / \mathrm{mL}$ in men).

Whereas the glucuronidation of BPA determines loss of the ability to interact with estrogen receptors, Volkel et al. ${ }^{33}$ suggested that this type of derivatization and rapid excretion are more effective in lowering the estrogenic activity of BPA in humans rather than in rats; therefore there are strain/related differences in the BPA metabolism, which may influence the difference in susceptibility to BPA toxicity between men and women.

Gender differences in serum BPA concentrations were found by Takeuchi et al. ${ }^{34}$ who investigated 14 healthy women, 11 men and 16 women with polycystic ovary syndrome. The results showed that BPA concentrations were significantly higher in men $(1.49 \pm 0.11 \mathrm{ng} / \mathrm{mL})$ and in women with polycystic ovary syndrome
$(1.04 \pm 0.10 \mathrm{ng} / \mathrm{mL})$ compared with normal women $(0.64 \pm 0.10 \mathrm{ng} / \mathrm{mL})$. Furthermore, there were significant positive correlations between serum BPA and total testosterone and free testosterone concentrations in all subjects but not with other sex-related hormone concentrations in any group. These findings suggest that the gender differences in serum BPA concentrations are possibly due to differences in the androgen-related metabolism of BPA.

The same research group ${ }^{34}$ sought to further investigate analyzed serum BPA in women with obesity and ovarian dysfunction (7 patients with hyperprolactinemia, 21 patients with hypothalamic amenorrhea, 13 non/obese and 6 obese patients with polycystic ovary syndrome): serum BPA concentrations were significantly higher in both non-obese and obese women with polycystic ovary syndrome $(1.05 \pm 0.10 \mathrm{ng} / \mathrm{mL}, 1.17 \pm 0.16 \mathrm{ng} / \mathrm{mL})$ and obese normal women $(1.04 \pm 0.09 \mathrm{ng} / \mathrm{mL})$ compared with those in non-obese normal women $(0.71 \pm 0.09 \mathrm{ng} / \mathrm{mL})$. Once again a significant correlation was found between androgen hormones (total testosterone, free testosterone, androstenedione and dehydroepiandrosterone sulfate) and serum BPA, in all subjects. The findings were explained by considering that it is generally known that obesity is associated with peripheral insulin resistance and hyperinsulinemia ${ }^{35}$ since hyperinsulinemia has a direct inhibitory effect on hepatic gender hormone binding globulin production and free testosterone and a biologically active fraction is higher in obese than in non obese women. The researchers speculated that the gender difference in serum BPA concentrations was due to differences in the androgen-related metabolism of BPA. Indeed, not only in men but also in hyperandrogenic women serum BPA levels are higher than in normal women.

Because BPA mimics estrogen action, via estrogen receptors in the endometrium, Hiroi et al. ${ }^{36}$ analyzed the BPA levels in patients with simple endometrial hyperplasia of a benign nature, complex endometrial hyperplasia with malignant potential and postmenopausal endometrial cancer: their findings suggest the presence of associations between BPA exposure and complex endometrial hyperplasia and endometrial cancer.

Hanaoka et $a l .{ }^{37}$ showed that occupational exposure to BPA may disrupt secretion of gonadotrophic hormones in men, studying a male working population (42 subjects) of epoxy resin sprayers; the clinical significance of endocrine disruption effects should be further investigated in order to understand whether females too could present a similar situation or whether there is a gender-specific effect. An association between serum BPA levels and recurrent miscarriage was reported:38 mean BPA levels were over three times as high in 45 women with a history of three or more consecutive first-trimester miscarriages compared to 32 non-parous women without fertility problems.

The Mothers and children's environmental health study, ${ }^{39}$ carried out in Korea since 2006, studied a cohort of 757 pregnant women, urinary BPA concentrations were analyzed and was found a significant association between BPA levels and birth weight, more pronounced in male neonates, and BPA levels and an increase of ponderal index in total, especially for females neonates.

Data from studies about BPA exposure of humans are recalled in Table $1.31,32,34,36$

Table 1. Data about human exposure to bisphenol A.

\begin{tabular}{|c|c|c|c|}
\hline Ref. & What did they observed? & Outcomes & What does it suggest? \\
\hline 31 & BPA levels in fetus plasma & $\begin{array}{l}\text { Higher concentrations in male than } \\
\text { female fetuses }\end{array}$ & $\begin{array}{l}\text { A correlation/interference with the male } \\
\text { hormonal system }\end{array}$ \\
\hline 32 & $\begin{array}{l}\text { Urinary BPA metabolites levels, } \\
\text { with a total BPA concentration similar }\end{array}$ & $\begin{array}{l}\text { Men showed higher glucuronidate BPA than women } \\
\text { Women appeared to have a metabolic shunt } \\
\text { for sulfation of BPA }\end{array}$ & $\begin{array}{l}\text { Preferentially a different metabolic pathway } \\
\text { between male and female }\end{array}$ \\
\hline 34 & BPA levels in serum & $\begin{array}{l}\text { Concentrations significantly higher in men and } \\
\text { in women with polycystic ovary syndrome, } \\
\text { compared with normal women } \\
\text { Significant positive correlation with androgens }\end{array}$ & $\begin{array}{l}\text { Correlation/interference of BPA with androgen } \\
\text { hormones }\end{array}$ \\
\hline 34 & $\begin{array}{l}\text { BPA levels in female serum with } \\
\text { different health problems } \\
\text { (obesity, ovarian dysfunction) }\end{array}$ & $\begin{array}{l}\text { Obese women and women with } \\
\text { polycystic ovary syndrome } \\
\text { showed higher level than normal women } \\
\text { Obesity is associated with hyperinsulinemia } \\
\text { that has a direct inhibitory effect on hepatic } \\
\text { gender hormone binding globulin production } \\
\text { and free testosterone }\end{array}$ & Correlation with androgen hormones \\
\hline 36 & $\begin{array}{l}\text { BPA levels in female plasma } \\
\text { with endometrial hyperplasia }\end{array}$ & $\begin{array}{l}\text { Association between BPA exposure and complex } \\
\text { endometrial hyperplasia and endometrial cancer }\end{array}$ & BPA acts as a xenoestrogen \\
\hline
\end{tabular}

BPA, bisphenol A. 


\section{Discussion and Conclusions}

The data collected thus far in the field of environmental toxicology are sufficiently robust to raise concerns about the potentially deleterious impact of BPA on humans. Recent studies indicate that in both rats and nonhuman primates, BPA abolishes estrogen dependent spine synapse formation in the hippocampus and prefrontal cortex, lending support to the use of animal models. ${ }^{40}$

BPA has been reported to bind estrogen receptors (ER $\alpha$ and $E R \beta)$ and play either estrogenic or antiestrogenic roles in vitro, it has been shown to have several actions such as uterotropic effects, ${ }^{41}$ decreasing sperm production, ${ }^{42}$ stimulation of prolactin release, ${ }^{43}$ and promotion of cell proliferation in a breast cancer cell line. ${ }^{44}$

Interaction with the endocrine system is without doubt a central role of BPA, because this substance could interact at different levels and determine different effects for men and women. Of course the interaction with the estrogen receptors and the ability to interfere with steroidogenesis strongly influence the possible health effects and adjustable gender difference plays a key role in understanding the real toxic outcomes. But, in addition to the risks related to the endocrine system, researchers should also evaluate the possible other areas that might be involved in exposure to BPA, in which, however, the male and female can live different situations and health problems.

Specifically it emerges that there are gender differences in serum BPA concentrations, possibly due to the difference in androgen-related enzyme activity levels, in fact male subjects (both fetus and adult one) showed, all the time, an higher level compared with the healthly female subjects, to equal levels of exposure.

Higher BPA levels in blood, in women, have been associated with a variety of conditions including obesity, endometrial hyperplasia, recurrent miscarriages, and polycystic ovarian syndrome; although providing interesting preliminary data on potential health risks, also considering gender difference, the epidemiological studies have several limitations. Above all, the studies have small sample sizes and limited details on subject selection criteria and are generally cross-sectional designs that include limited checks on potential confounders. These limitations, in the study design, contribute to the limited ability to draw conclusions based on the epidemiology of potential health risks related to BPA.

Further investigation is needed, with epidemiological and statistical validity, in order to clarify the different possible effects for men or women, also in a perspective of prevention of specific risk in life and occupational settings.

Toxicologists could take in greater account the role of sex on health effects in their research protocols; the physician at work should establish a health protocol, taking gender difference into account, because, even in the same exposure conditions, men and women could manifest different health effects.

\section{Research highlights}

BPA acts as a xenoestrogen.

Different health outcomes, between male and female, are recordable following exposure to bisphenol A.

Different toxicological parameters identified, hypothesized different metabolic pathway, with regard to sex difference.

Necessity, in toxicology, to compare results from surveys about man and woman, for different xenobiotics, so to identify potential differences, particularly if endocrine disruptors chemicals.

\section{References}

1. Kennedy S, Koehoorn M. Exposure assessment in epidemiology: does gender matter? Am J Ind Med 2003;44:584-94.

2. Gochfeld M. Framework for gender differences in human and animal toxicology. Environ Res 2007;104: 4-21.

3. Rost D, Kopplow K, Gehrke S, Mueller S, Friess $\mathrm{H}$, Ittrich $\mathrm{C}$, et al. Gender specific expression of liver organic anion transporters in rat. Eur J Clin Invest 2005;35: $635-43$.

4. Schwartz JB. The influence of sex on pharmacokinetics. Clin Phamacokinet 2003;42:107-21.

5. Ernstgård L, Sjogren B, Warholm M, Johanson G. Sex differences in the toxicokinetics of inhaled solvent vapors in humans. 2. 2-Propanol. Toxicol Appl Pharmacol 2003;193:158-67.

6. Ghandi M, Aweeka F, Greenblatt RM, Blaschke TF. Sex differences in pharmacokinetics and pharmacodynamics. Annu Rev Pharmacol Toxicol 2004;44:499-523.

7. International Commission on Radiological Protection (ICRP). Basic anatomical and physiological data for use in radiological protection: reference values. ICRP Publication n. 89. Ann ICRP 2002;32:3-4.

8. Kadiri S, Ajayi SO. Variability in the relationship between serum creatinine and creatinine clearance in hypertensives and normotensives with normal renal function. Afric J Med Sci 2000;29:93-6.

9. Burger J, Fossi C, McClellan-Green P,
Orlando EF. Methodologies, bioindicators, and biomarkers for assessing genderrelated differences in wildlife exposed to environmental chemicals. Environ Res 2007;104:135-52.

10. Arbuckle TE. Are there sex and gender differences in acute exposure to chemicals in the same settings? Environ Res 2006;101: 195-204.

11. Groshart CP, Okkerman PC, Pijnenburg AMCM. Chemical study on BPA. Ministerie van Verkeer en Waterstaat-DirectoraatGeneraal Rijkswaterstaat; 2001.

12. Santillana Mi, Ruiz E, Nieto MT, Bustos J, Maia J, Sendon R, et al. Migration of bisphenol A from polycarbonate baby bottles purchased in the Spanish market by liquid chromatography and florescence detection. Food Addit Contam Part A Chem Anal Control Expo Risk Assess 2011;28: 1610-8.

13. Konieczna A, Rutkowska A, Rachon D. Health risk of exposure to bisphenol A (BPA). Rocz Panstw Zakl Hig 2015;66:5-11.

14. CSTEE Scientific Committee on toxicity, ecotoxicity and environment. Opinion on the results of the risk assessment of: Bisphenol A - Human health part. Opinion expressed at the 31th CSTEE plenary meeting, 22 May 2002, Brussels.

15. Rezg R, El Fazaa S, Gharbi N, Mornagui B. Bisphenol A and human chronic diseases: current evidences, possible mechanisms, and future perspectives. Environ Int 2014;64:83-90.

16. Rochester JR. Bisphenol A and human health: a review of the literature. Reprod Toxicol 2013;42:132-55.

17. Wiese TE, Ostby JS, Kelce WR. The estrogenic capacity of bisphenol analogues and metabolites in mammalian cell proliferation and reporter gene assays. Toxicologist 1998;42:98.

18. Wisniewski P, Romano RM, Kizys MM, Oliveira KC, Kasamatsu T, Giannocco G, et al. Adult exposure to bisphenol A (BPA) in Wistar rats reduces sperm quality with disruption of the hypothalamic-pituitary-testicular axis. Toxicology 2015;329:1-9.

19. Shibata N, Matsumoto J, Nakada K, Yuasa A, Yokota H. Male specific suppression of hepatic microsomal UDP-glucuronosyltransferase activity toward sex hormones in the adult male rat administered bisphenol A. Biochem J 2002;368:783-8.

20. Rubin BS, Lenkowski JR, Schaeberle CM, Vandenberg LN, Ronsheim PM, Soto AM. Evidence of altered brain sexual differentiation in mice exposed perinatally to low, environmentally relevant levels of bisphenol A. Endocrinol 2006;147:3681-91.

21. Funabashi T, Kawaguchi M, Furuta M, Fukushima A, Kimura F. Exposure to bisphenol A during gestation and lactation 
causes loss of sex difference in corticotropin-releasing hormone immunoreactive neurons in the bed nucleus of the stria terminalis of rats. Psychoneuroendocrinol 2004;29:475-85.

22. Ferguson SA, Law CD, Kissling GE. Developmental treatment with ethinyl estradiol, but not bisphenol A, causes alterations in sexually dimorphic behaviors in male and female Sprague Dawley rats. Toxicol Sci 2014;140:374-92.

23. Gioiosa L, Parmigiani S, Vom Saal FS, Palanza P. The effects of bisphenol A on emotional behavior depend upon the timing of exposure, age and gender in mice. Horm Behav 2013;63:598-605.

24. Diaz Weinstein S, Villafane JJ, Juliano N, Bowman RE. Adolescent exposure to bisphenol A increases anxiety and sucrose preference but impairs spatial memory in rats independent of sex. Brain Res 2013;1529:56-65.

25. Xu X, Tian D, Hong X, Chen L, Xie L. Sexspecific influence of exposure to bisphenol-A between adolescence and young adulthood on mouse behaviors. Neuropharmacol 2011;61:565-73.

26. Rebuli ME, Cao J, Sluzas E, Delclos KB, Camacho L, Lewis SM, et al. Investigation of the effects of subchronic low dose oral exposure to bisphenol A (BPA) and ethinyl estradiol (EE) on estrogen receptor expression in the juvenile and adult female rat hypothalamus. Toxicol Sci 2014;140:190-203.

27. Cao J, Mickens JA, McCaffrey KA, Leyrer SM, Patisaul HB. Neonatal bisphenol A exposure alters sexually dimorphic gene expression in the postnatal rat hypothalamus. Neurotoxicology 2012;33:23-36.

28. Takeuchi T, Tsutsumi 0, Nakamura N, Ikezuki Y, Takai Y, Yano T, et al. Gender difference in serum bisphenol A levels may be caused by liver UDP-glucuronosyltransferase activity in rats. Biochem Biophys Res Communications 2004;325:549-54.

29. Van Esterik JC, Dollè ME, Lamoree MH, van Leeuwen SP, Hamers T, Legler J, et al. Programming of metabolic effects in C57BL/6JxFVB mice by exposure to bisphenol A during gestation and lactation. Toxicology 2014;321:40-52.

30. Taylor JA, vom Saal FS, Welshons WV, Drury B, Rottinghaus G, Hunt PA, et al. Similarity of bisphenol A pharmacokinetics in rhesus monkeys and mice: relevance for human exposure. Environ Health Perspec 2011;119:422-30.

31. Schonfelder G, Wittfoht W, Hopp H, Talsness CE, Paul M, Chahoud I. Parent bisphenol A accumulation in the human maternal fetal placental unit. Environ Health Perspec 2002;110:A703-7.

32. Kim YH, Kim CS, Park S, Han SY, Pyo MY, Yang M. Gender differences in the levels of bisphenol A metabolites in urine. Biochem Biophys Res Comm 2003;312:441-8.

33. Volkel W, Colnot T, Csanady GA, Filser JG, Dekant W. Metabolism and kinetics of bisphenol A in humans at low doses following oral administration. Chem Res Toxicol 2002;15:1281-7.

34. Takeuchi T, Tsutsumi 0. Serum bisphenol A concentrations showed gender differences, possibly linked to androgen levels. Biochem Biophys Res Communications 2002;291:76-8.

35. Peris AN, Sothmann MS, Aiman EJ, Kissebeh AH. The relationship of insulin to sex hormone-binding globulin: role of adiposity. Fertil Steril 1989;52:69-72.

36. Hiroi H, Tsutsumi 0, Takeuchi T, Momoeda M, Ikezuki Y, Okamura A, et al. Differences in serum bisphenol A concentrations in premenopausal normal women and women with endometrial hyperplasia.
Endocr J 2004;51:595-600.

37. Hanaoka T, Kawamura N, Hara K, Tsugane $\mathrm{S}$. Urinary bisphenol A and plasma hormone concentrations in male workers exposed to bisphenol A diglycidyl ether and mixed organic solvents. Occup Environ Med 2002;59:625-8.

38. Sugiura-Ogasawara M, Ozaki Y, Sonta SI, Makino T, Suzumori K. Exposure to bisphenol A is associated with recurrent miscarriage. Hum Reprod 2005;20:2325-9.

39. Lee BE, Park H, Hong YC, Ha M, Kim Y, Chang N, et al. Prenatal bisphenol A and birth outcomes: MOCEH (Mothers and Children's Environmental Health) study. Int J Hyg Environ Health 2014;217:328-34.

40. Leranth C, Hajszan T, Szigeti-Buck K, Bober J, MacLusky NJ. Bisphenol A prevents the synaptogenic response to estradiol in hippocampus and prefriontal cortex of ovariectomized nonhuman primates. Proc Natl Acad Sci U S A 2008;105:14187-91.

41. Ashby J, Tinwell H. Uterotrophic activity of bisphenol A in the immature rat. Environ Health Perspec 1998;106:719-20.

42. Vom Staal FS, Cooke PS, Buchanan DL, Palanza P, Thayer KA, Nagel SC, et al. A physiologically based approach to the study of bisphenol A and other estrogenic chemicals on the size of reproductive organs, daily sperm production and behavior. Toxicol Ind Health 1998;14:239-60.

43. Steinmetz R, Brown NG, Allen DL, Bibsby RM, Benjonathan N. The environmental estrogen bisphenol A stimulates prolactin release in vitro and in vivo. Endocrinol 1997;138:1780-6.

44. Kitamura S, Suzuki T, Sanoh S, Kohta R, Jinno N, Sugihara K, et al. Comparative study of the endocrine disrupting activity of bisphenol A and 19 related compounds. Toxicol Sci 2005;84:249-59. 